\title{
Effect of Initial Grain Size on Dynamically Recrystallized Grain Size in AZ31 Magnesium Alloy
}

\author{
Yorinobu Takigawa, Masayoshi Honda*, Tokuteru Uesugi and Kenji Higashi \\ Department of Materials Science, Graduate School of Engineering, Osaka Prefecture University, Sakai 599-8531, Japan
}

The effect of initial grain size on dynamically recrystallized grain size (DRX grain size) is examined in AZ31 magnesium alloy with four kinds of initial grain sizes. When the average grain size after the high-temperature compression test is plotted against Zenner-Hollomon parameter ( $Z$-parameter), initial grain size dependence on DRX grain size appears only in the specimen with large initial grain size in the low $Z$ region, but not in the specimen with small grain size or in high $Z$ region. When the grain size measured only in recrystallized region is plotted against $Z$-parameter, initial grain size dependence on DRX grain size does not appear. From these results, it is concluded that there is no initial grain size dependence on DRX grain size when the DRX proceeds to some degree, because the DRX grain size becomes constant for a given $Z$ value. The initial grain size dependence on DRX grain size observed in the low $Z$ region would be related to the rotation of basal plane perpendicular to the compression axis during deformation before the DRX grains have been developed sufficiently. [doi:10.2320/matertrans.MAW200829]

(Received April 25, 2008; Accepted June 27, 2008; Published August 13, 2008)

Keywords: magnesium alloy, dynamic recrystallization, grain refinement, Z-parameter, initial grain size

\section{Introduction}

Recently, there has been a significant increase in the use of magnesium alloys as a structural material because of the lightness of magnesium. Especially, the use of magnesium alloys is increasing in many components of mobile electronic appliances such as cellular phones and notebook computers. This is not only due to the low density of magnesium but also its high modulus, heat dissipation, electromagnetic shielding, and "metallic feel" such as luster that gives a sense of quality. ${ }^{1)}$ Die casting and injection molding are the main method of manufacturing such components, ${ }^{2)}$ however, plastic forming technologies such as hot drawing and hot forging with high productivity have been developed to form thinner walls of the components without defects. ${ }^{3,4)}$ In the drawing process, it has been clearly demonstrated that the critical strain rate increase with the refinement of grain size in AZ31 magnesium alloy at $523 \mathrm{~K}^{5}{ }^{5}$ Thus, grain size refinement of magnesium alloys is essential not only for the development of superior mechanical properties at room temperature such as higher strength, toughness ${ }^{6,7)}$ and ductility, ${ }^{8)}$ but also for the higher productivity.

In general, dynamic restoration behavior is dependent on the stacking fault energy (SFE) and lattice diffusivity. ${ }^{9,10)}$ Recent studies have found that the stacking fault energy (SFE) of magnesium alloys is smaller than that of a typical light metal, i.e. aluminum. ${ }^{1-14)}$ This suggests that grain refinement by dynamic recrystallization (DRX) readily occurs in magnesium, and thus, hot deformation accompanied by DRX should be a promising method for refining microstructures. To date, the grain refinement due to DRX during hot deformation has been demonstrated in conventional $\mathrm{Mg}-\mathrm{Al}-\mathrm{Zn}$ alloys. ${ }^{15-28)}$ It has been reported that dynamically recrystallized grain size (DRX grain size) decreases with an increase of Zener-Hollomon parameter $(Z \text {-parameter })^{29)}$ in several magnesium alloys. ${ }^{19,24,27,30,31)}$ Watanabe et al. have reported that there is initial grain sizes

*Graduate Student, Osaka Prefecture University dependence on DRX grain size in AZ61 magnesium alloy. ${ }^{19)}$ However, there have little reports on such initial grain sizes dependence on DRX grain size in other magnesium alloys. In the present study, DRX behavior in AZ31 magnesium alloy with different grain size was examined in order to investigate the initial grain size dependence on DRX grain size.

\section{Experimental Procedure}

The material used in this study was a commercial AZ31 magnesium alloy. Four kinds of specimens with different grain size were prepared by annealing after extrusion. The initial grain size of each specimen was 7, 20, 38, 60 $\mu \mathrm{m}$, respectively. The microstructure of the specimens is shown in Fig. 1. The grains were almost equiaxed in all the materials examined. Although the grain size distribution may be different in each specimen in Fig. 1, the analysis is conducted assuming that DRX occurs similarly in all the grains in this study. Compression test samples with diameter of $6 \mathrm{~mm}$ and height of $8 \mathrm{~mm}$ were prepared such that the compression direction coincidence with the extruded direction. Uniaxial compression tests were conducted at a temperature range between 473 and $573 \mathrm{~K}$, and at a strain rate range of $3 \times 10^{-4}$ to $3 \times 10^{-2} \mathrm{~s}^{-1}$. Deformation was carried out to the true strain of 1.0. The samples were quenched within $5 \mathrm{~s}$ after testing so as to retain the microstructure. The metallographic analysis was carried out by optical microscopy (OM) and orientation imaging microscopy (OIM). The grain size, $d$, was measured by the linear intercept method $(d=1.74 l ; l$ is the linear intercept size) from the OM images. The average grain sizes, $d_{\mathrm{av}}$, is estimated from whole area of the image. In the estimation, grain size distribution is not considers. The DRX grain size, $d_{\text {rec }}$, is estimated only from the region of dynamically developed grains.

\section{Results and Discussion}

Figure 2 shows the optical microstructure of specimens deformed to $\varepsilon=1.0$ in AZ31 alloys: (1) initial grain size 

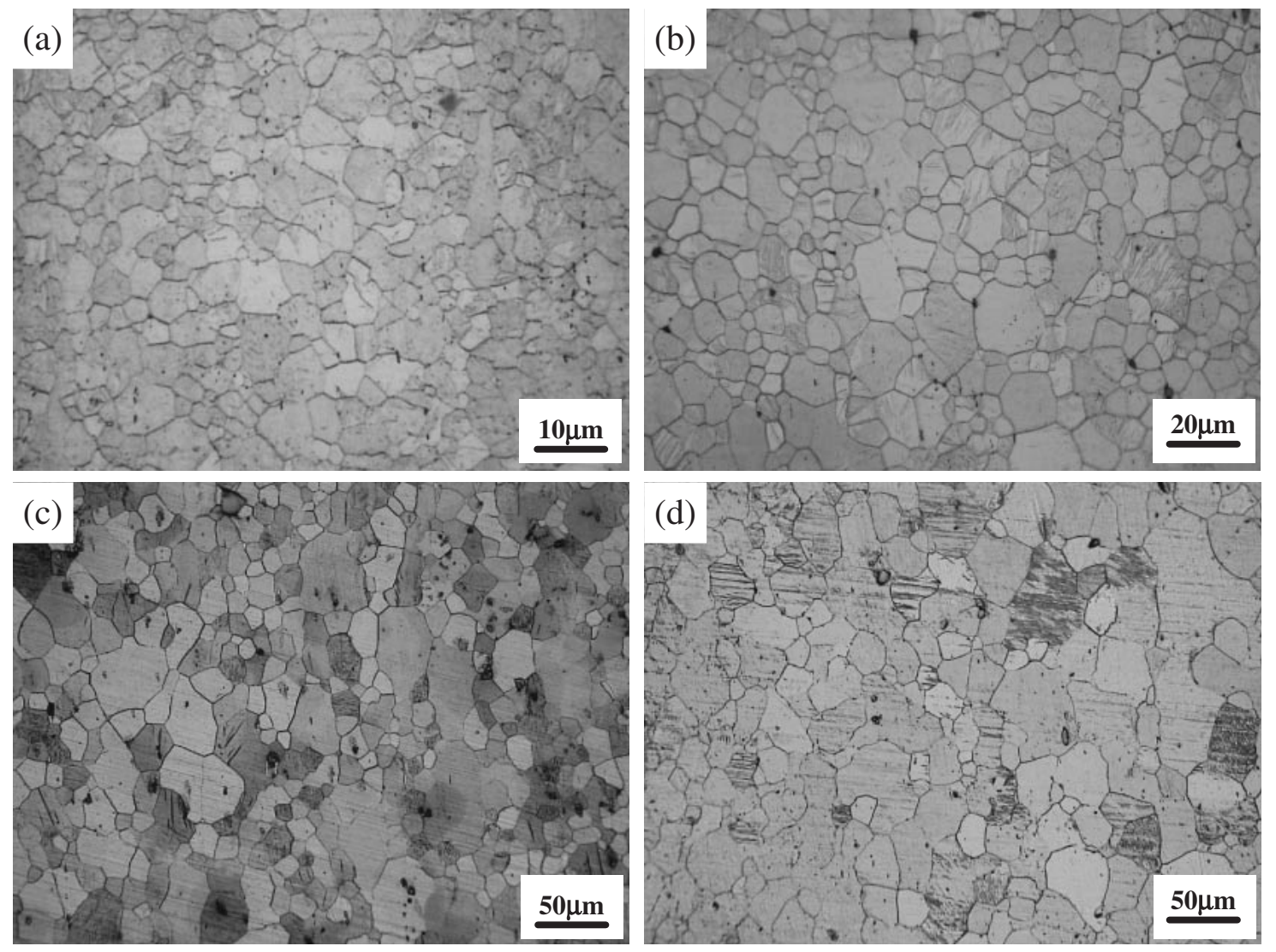

Fig. 1 Typical microstructure of undeformed specimens of AZ31 alloy with initial grain sizes of (a) $7 \mu \mathrm{m}$, (b) $20 \mu \mathrm{m}$, (c) $38 \mu \mathrm{m}$ and (d) $60 \mu \mathrm{m}$.
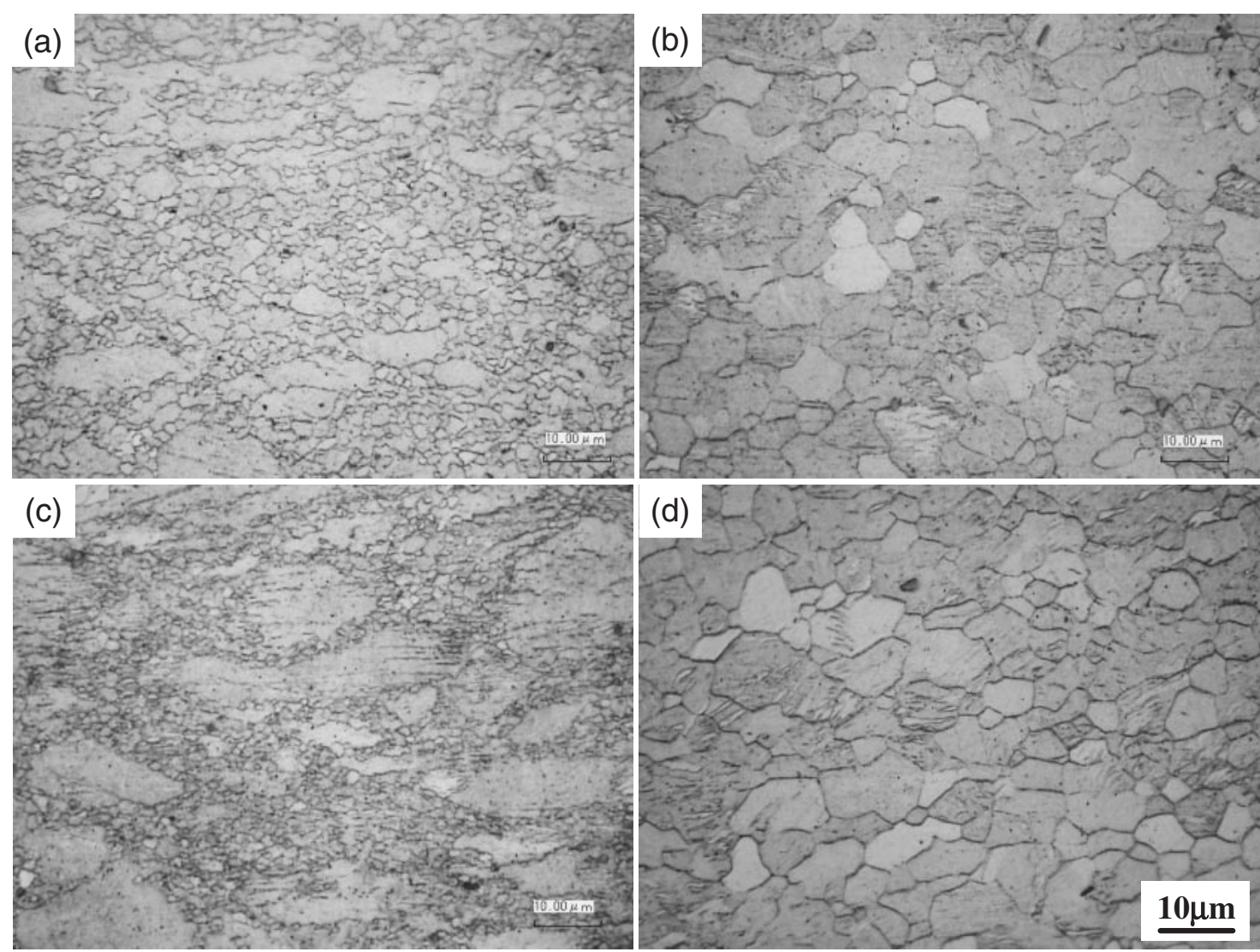

Fig. 2 Optical microstructure of specimens deformed to $\varepsilon=1.0$ in AZ31 alloys: (a) initial grain size of $20 \mu \mathrm{m}$ and deformed at $523 \mathrm{~K}$ and at a strain rate of $3 \times 10^{-2} \mathrm{~s}^{-1}$, (b) initial grain size of $20 \mu \mathrm{m}$ and deformed at $573 \mathrm{~K}$ and $3 \times 10^{-4} \mathrm{~s}^{-1}$, (c) initial grain size of $38 \mu \mathrm{m}$ and deformed at $523 \mathrm{~K}$ and $3 \times 10^{-2} \mathrm{~s}^{-1}$ and (d) initial grain size of $38 \mu \mathrm{m}$ and deformed at $573 \mathrm{~K}$ and $3 \times 10^{-4} \mathrm{~s}^{-1}$. 


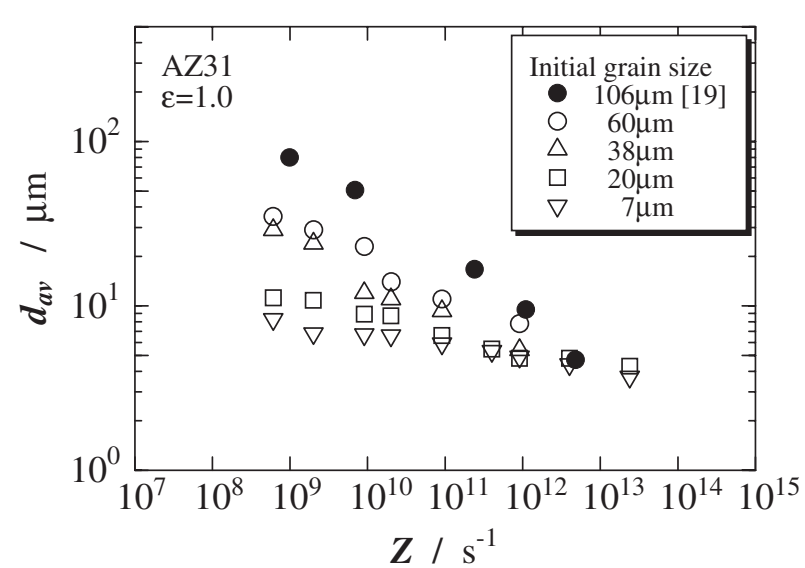

Fig. 3 The relationship between average grain size and $Z$-parameter in AZ31 alloy.

of $20 \mu \mathrm{m}$ and deformed at $523 \mathrm{~K}$ and at a strain rate of $3 \times 10^{-2} \mathrm{~s}^{-1}$, (2) initial grain size of $20 \mu \mathrm{m}$ and deformed at $573 \mathrm{~K}$ and $3 \times 10^{-4} \mathrm{~s}^{-1}$, (3) initial grain size of $38 \mu \mathrm{m}$ and deformed at $523 \mathrm{~K}$ and $3 \times 10^{-2} \mathrm{~s}^{-1}$ and (4) initial grain size of $38 \mu \mathrm{m}$ and deformed at $573 \mathrm{~K}$ and $3 \times 10^{-4} \mathrm{~s}^{-1}$, respectively. DRX occurred in all the conditions examined and the average grain size $\left(d_{\mathrm{av}}\right)$ was estimated to be 4.8, 11, 5.4 and $29 \mu \mathrm{m}$, respectively. In Fig. 2(a) and (c), non-recrystallized region was partially observed in both conditions but the $d_{\mathrm{av}}$ was almost the same in the two conditions. In contrast, the grains were almost equiaxed in Fig. 2(b) and (d) but the $d_{\mathrm{av}}$ was much different in the two conditions.

Figure 3 shows the relationship between $d_{\mathrm{av}}$ and $Z$ parameter $(=\dot{\varepsilon} \exp (Q / R T))$ in all the specimens examined, where $Q$ is taken to be the activation energy for the lattice diffusion of magnesium, $135 \mathrm{~kJ} / \mathrm{mol}^{32)}$ The data reported by Watanabe et al. ${ }^{19)}$ are also plotted in the figure. The $d_{\mathrm{av}}$ decreases as the $Z$-value increases. The relationship between $Z$ and the DRX grain size, $d$, may be given by

$$
Z d^{m}=A
$$

where $m$ is the grain size exponent and $A$ is a constant. The relationship varies depending on the $Z$-value and the initial grain size. In the low $Z$ region, the $d_{\mathrm{av}}$ is highly dependent on initial grain size, i.e., the $d_{\mathrm{av}}$ is larger when the initial grain size is large. When the initial grain size is large, the $m$ value is estimated to be about 3 , which is in good agreement with the value reported in some previous works. ${ }^{19,24,27,31)}$ However, the $m$ value increases with decreasing initial grain size to be about 8 . In the high $Z$ region, there is no initial grain size dependence on $d_{\mathrm{av}}$, and the $m$ value is also about 8 . This value is close to the $m$ value of 6 reported recently in hot compression tests in AZ31 alloy with an initial grain size of $35 \mu \mathrm{m} .^{28)}$

Figure 4 shows the relationship between the grain size measured in recrystallized region $\left(d_{\text {rec }}\right)$ and $Z$-parameter in AZ31 alloy. The result exhibits approximately single straight line, and no initial grain size dependence on $d_{\text {rec }}$ is found. The $m$ value is estimated to be about 6 , which is in good agreement with the $m$ value obtained in the high $Z$ region in Fig. 3. This value is also in good agreement with the $m$

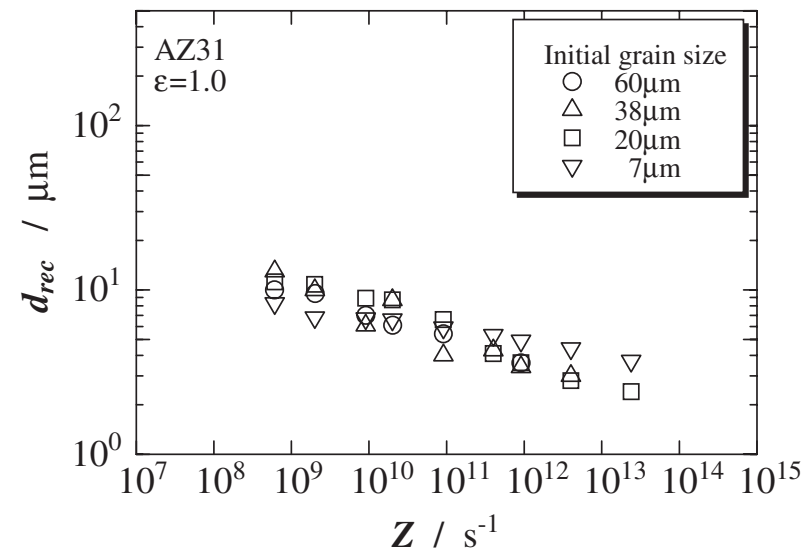

Fig. 4 The relationship between the grain size measured in dynamically recrystallized region and Z-parameter in AZ31 alloy.

value obtained in the extruded AZ31 alloy with initial grain size of $80 \mu \mathrm{m}$ extruded at 513 and $613 \mathrm{~K}$ and at a strain rate of $0.1 \mathrm{~s}^{-1}$ to a strain of 3.7 in our previous result. ${ }^{33)}$

From the results shown in Figs. 3 and 4, DXR seems to proceed to some degree where the DRX grain size become constant in high $Z$ region or in the specimen with small grain size even in low $Z$ region. In contrast, DRX grain seems not to be developed sufficiently in the specimen with large grain sizes in low $Z$ region even at the strain of 1.0. This trend is in good agreement with the previous result that the AZ31 alloy with larger grain size need more strain for the fraction of recrystallized region to be saturated. ${ }^{21)}$ This result would be related to the rotation of basal plane of magnesium perpendicular to the compression axis during deformation, because kink band by which new grains are evolved are formed roughly perpendicular to the basal plane. ${ }^{21)}$

Figure 5 shows a typical OIM map and an inverse pole figure from the direction of the compression axis of AZ31 alloy with initial grain size of $60 \mu \mathrm{m}$ deformed at $523 \mathrm{~K}$ and at a strain rate of $3 \times 10^{-4} \mathrm{~s}^{-1}$ to the strain of 1.0. It is clearly shown that the [0001] direction is highly oriented parallel to the compression axis. Similar results are obtained in all the specimens examined that the [0001] direction is highly oriented parallel to the compression axis at the strain of 1.0.

From these results, it is shown that there is no initial grain size dependence on DRX grain size when the DXR proceeds to some degree, because the DRX grain size becomes constant for a given $Z$-value. In such a case, the grain size exponent, $m$, in eq. (1) is about 6 independent on the initial grain size. The initial grain size dependence on DRX grain size observed in the low $Z$ region would be related to the result that the rotation of basal plane perpendicular to the compression axis occurs during deformation before the DRX grains have been developed sufficiently in the specimen with large grain sizes even at the large strain of 1.0, and that the larger grain size remains in comparison with almost constant grain size of $d_{\text {rec }}$. Detailed analysis on the change in orientation distribution and the volume fraction and size of $d_{\text {rec }}$ with strain will be conducted to understand the mechanism in future works. 

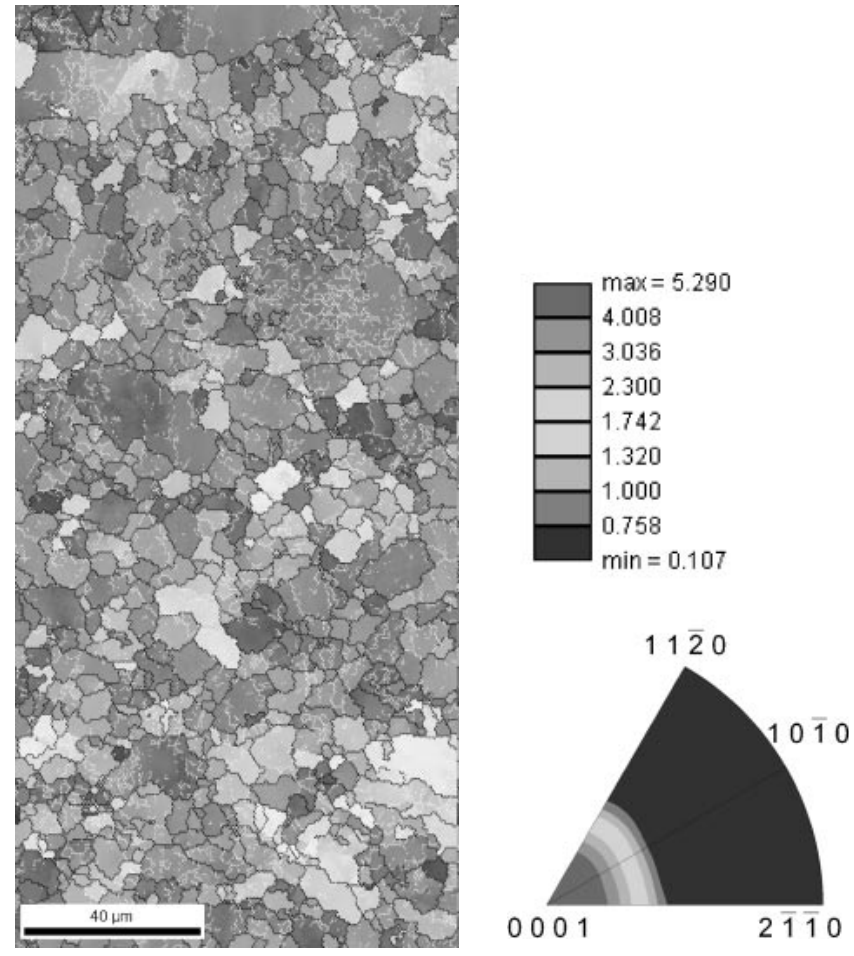

Fig. 5 A typical OIM map and an inverse pole figure from the direction of the compression axis of AZ31 alloy with initial grain size of $60 \mathrm{~m}$ deformed at $523 \mathrm{~K}$ and at a strain rate of $3 \times 10^{-4} \mathrm{~s}^{-1}$.

\section{Conclusion}

In this study, the effect of initial grain size on DRX grain size is examined in AZ31 magnesium alloy with four kinds of initial grain sizes. When the average grain size is plotted against Z-parameter, initial grain size dependence appears only in the specimen with large initial grain size in the low $Z$ region, but not in the specimen with small grain size or in high $Z$ region. When the grain size measured only in recrystallized region is plotted against $Z$-parameter, initial grain size dependence does not appear. From these results, it is concluded that there is no initial grain size dependence on DRX grain size when the DRX proceeds to some degree, because the DRX grain size becomes constant for a given $Z$-value. In such a case, the grain size exponent, $m$, in eq. (1) is about 6 independent on the initial grain size. The initial grain size dependence on DRX grain size observed in the low $Z$ region would be related to the rotation of basal plane perpendicular to the compression axis during deformation before the DRX grains have been developed sufficiently.

\section{Acknowledgement}

This study was conducted with financial support from
"Forged Magnesium Parts Technological Development Project" which is organized by New Energy and Industrial Technology Development Organization (NEDO), Japan.

\section{REFERENCES}

1) M. Ohara, H. Okahara, Y. Takigawa and K. Higashi: Mater. Trans. 49 (2008) 909-912.

2) Y. Kojima and S. Kamado: Engineering Materials 50 (2002) 18-24.

3) T. Shimizu: Alutopia 31-4 (2001) 41-44.

4) H. Okahara, M. Ohara, Y. Takigawa and K. Higashi: Mater. Trans. 47 (2006) 954-958.

5) A. Takara: Doctoral Dissertation, Osaka Prefecture University, 2006.

6) H. Somekawa and T. Mukai: Scripta Mater. 53 (2005) 1059.

7) H. Somekawa, A. Singh and T. Mukai: Mater. Trans. 48 (2007) 1422-1426.

8) T. Mukai, M. Yamanoi, H. Watanabe, K. Ishikawa and K. Higashi: Mater. Trans. 42 (2001) 1177-1181.

9) T. Sakai and M. Ohashi: Tetsu-to-Hagane 67 (1981) 200-2009.

10) T. Sakai and J. J. Jonas: Acta Metall. 32 (1984) 189-209.

11) N. Chetty and M. Weinert: Phys. Rev. B 56 (1997) 10844-10851.

12) T. Uesugi, M. Kohyama, M. Kohzu and K. Higashi: Mater. Sci. Forum 419-422 (2003) 225-230.

13) H. Somekawa, K. Hirai, H. Watanabe, Y. Takigawa and K. Higashi: Mater. Sci. Eng. A 407 (2005) 53-61.

14) A. E. Smith: Surf. Sci. 601 (2007) 5762-5765.

15) H. Takuda, S. Kikuchi and N. Hatta: J. Mater. Sci. 27 (1992) 937-940.

16) A. Mwembela, E. B. Konopleva and H. J. McQueen: Scr. Mater. 37 (1997) 1789-1795.

17) T. Mohri, M. Mabuchi, M. Nakamura, T. Asahina, H. Iwasaki, T. Aizawa and K. Higashi: Mater. Sci. Eng. A 290 (2000) 139-144.

18) Y. Chino, M. Mabuchi, K. Shimojima, Y. Yamada, C. Wen, K. Miwa, M. Nakamura, T. Asahina, K. Higashi and T. Aizawa: Mater. Trans. 42 (2001) 414-417.

19) H. Watanabe, H. Tsutsui, T. Mukai, H. Ishikawa, Y. Okanda, M. Kohzu and K. Higashi: Mater. Trans. 42 (2001) 1200-1205.

20) X. Yang, H. Miura and T. Sakai: Mater. Trans. 44 (2003) 197-203.

21) X. Yang, H. Miura and T. Sakai: Mater. Sci. Forum 426-432 (2003) 611-616.

22) M. R. Barnett: Mater. Trans. 44 (2003) 571.

23) Y. Chino, M. Kobata, H. Iwasaki and M. Mabuchi: Acta Mater. 51 (2003) 3309.

24) A. Takara, Y. Nishikawa, H. Watanabe, H. Somekawa, T. Mukai and K. Higashi: Mater. Trans. 45 (2004) 2531-2536.

25) J. Xing, H. Soda, X. Yang, H. Miura and T. Sakai: Mater. Trans. 46 (2005) 1646-1650.

26) D. L. Yin, K. F. Zhang, G. F. Wang and W. B. Han: Mater. Sci. Eng. A 392 (2005) 320.

27) K. Hirai, H. Somekawa, Y. Takigawa and K. Higashi: Scripta Mater. 56 (2007) 237-240.

28) S. M. Fatemi-Varzaneh, A. Zarei-Hanzaki and H. Beladi: Mater. Sci. Eng. A 456 (2007) 52-57.

29) C. Zener and J. H. Hollomon: J. Appl. Phys. 15 (1944) 22-32.

30) R. O. Kaibyshev, A. M. Galiev and B. K. Sokolov: Phys. Met. Metall. 78 (1994) 209-217.

31) M. Mabuchi, K. Kubota and K. Higashi: Mater. Trans., JIM 36 (1995) 1249-1254.

32) H. J. Frost and M. F. Ashby: Deformation-mechanism Maps, (Pergamon Press, Oxford, 1982) p. 44.

33) M. Honda, T. Uesugi, Y. Takigawa, H. Mabuchi and K. Higashi: Adv. Mater. Res. 26-28 (2007) 449-452. 